\title{
SARA RODRIGUES GARBIN
}

\section{ESTUDO DA INTERAÇÃO DOS HORMÔNIOS SEXUAIS FEMININOS NA INFLAMAÇÃO LOCAL, SISTÊMICA E PULMONAR CAUSADA PELA ISQUEMIA E REPERFUSÃO INTESTINAL EM CAMUNDONGOS FÊMEAS OBESAS}

Dissertação apresentada ao Programa de PósGraduação em Farmacologia do Instituto de Ciências Biomédicas da Universidade de São Paulo, para a obtenção do Título de Mestre em Ciências.

Área de Concentração: Farmacologia

Orientador: Prof. Dr. Wothan Tavares de Lima

Versão corrigida. A versão original eletrônica, encontra-se disponível tanto na Biblioteca do ICB quanto na Biblioteca Digital de Teses e Dissertações da USP (BDTD) 


\section{RESUMO}

Rodrigues-Garbin, S. Estudo da interação dos hormônios sexuais femininos na inflamação local, sistêmica e pulmonar causada pela isquemia e reperfusão intestinal em camundongos fêmeas obesas. 2017. 106 f. Dissertação (Mestrado Farmacologia) - Instituto de Ciências Biomédicas - Universidade de São Paulo, São Paulo, 2017.

A obesidade determina inflamação sistêmica crônica de baixo grau caracterizada pela geração de mediadores pró-inflamatórios a partir do tecido adiposo. A isquemia e reperfusão (IR) intestinal induz inflamação local, sistêmica e pulmonar na qual os hormônios sexuais femininos (HSF), notadamente o estradiol, exerce importante efeito modulador. Neste estudo investigamos a interação da obesidade com os HSF sobre as repercussões da IR intestinal. Para tanto, camundongos fêmeas C57BI/6 submetidos ou não à remoção dos ovários $(\mathrm{OVx})$ e mantidos com dieta hiperlipídica (9 semanas) para indução da obesidade. Como controle, foram usados animais obesos mantidos com os ovários intactos (Não OVx). Os animais obesos foram submetidos à IR intestinal (45 min, obstrução da artéria mesentérica superior) seguida de $2 \mathrm{~h}$ de reperfusão intestinal. Os nossos dados indicaram que somente a OVx em comparação a animais Não OVx, ambos obesos, aumentou a permeabilidade vascular e a atividade da enzima mieloperoxidase (MPO) no intestino e no pulmão, além de aumentar o infiltrado de células no pulmão. Observou-se aumento de linfócitos, granulócitos e plaquetas circulantes. Também verificamos elevados níveis séricos de leptina, interleucina (IL) IL-17A, KC e fator de crescimento endotelial vascular (VEGF). Ainda foi observada redução sérica de IL-6 e resistina. Além disso houve elevação da concentração sérica de fosfatase alcalina, mas não de lactato desidrogenase (LDH). No pulmão detectamos aumento de nitrito e expressão de iNOS. No tecido pulmonar houve aumento de IL-5 e IL-10 e, redução de leptina, IL-17A, KC e IL-6. No tecido adiposo elevou a concentração de KC, MIP2 , IL-6, leptina e resistina. Após os animais serem submetidos à IR intestinal os parâmetros analisados nos animais OVx exacerbaram-se em relação aos animais Não OVx. Ainda relatamos aumento de produção de células da medula óssea, redução do complexo $\mathrm{CD} 45^{+} / \mathrm{CD} 41^{+}$e aumento do complexo $\mathrm{CD} 11 \mathrm{~b}^{+} / \mathrm{CD} 162^{+}$. Observamos aumento de nitrito e expressão de iNOS no pulmão mas redução da expressão de eNOS. A IR intestinal nos animais OVx aumentou os níveis séricos de leptina, IL-17A, KC e reduziu o de resistina. Também houve elevação de geração no pulmão de VEGF e IL-1ß enquanto o tecido adiposo elevou KC, MIP-2, IL-6, leptina e resistina.

Tomados em conjunto, nossos dados gerados sugerem que a redução prolongada dos HSF causada pela OVx associada à obesidade induz a um certo grau de inflamação intestinal, sistêmica e pulmonar e que a IR intestinal pode acentuar a inflamação sendo o pulmão possivelmente mais sensível.

Palavras chave: Obesidade. Ovariectomia. Hormônios Sexuais Femininos. Inflamação Pulmonar. Isquemia e Reperfusão Intestinal. 


\begin{abstract}
Rodrigues-Garbin, S. The role of female sexual hormones on local, systemic and pulmonary inflammation caused by intestinal ischemia and reperfusion in obese female mice. 2017. MS thesis (Pharmacology) - Institute of Biomedical Sciences, University of São Paulo, São Paulo, 2017.
\end{abstract}

Obesity determines a low-grade chronic systemic inflammation characterized by generation of pro-inflammatory mediators from adipose tissue. Intestinal ischemia and reperfusion (IR) induce local, systemic and pulmonary inflammation in which female sex hormones (FSH), notably estradiol, exert an important modulating effect. In this study we investigated the interaction of obesity with $\mathrm{FSH}$ on the repercussions of intestinal IR. For this, female C57BI/6 mice submitted or not to ovarian removal (OVx) were maintained (9 weeks) on a hyperlipidic diet for induction of obesity. As controls, obese animals were kept with intact ovaries (Non-OVx). Obese animals were submitted to intestinal IR (45 min, superior mesenteric artery obstruction, followed by $2 \mathrm{~h}$ of intestinal reperfusion). Our data indicated that only OVx in comparison to Non-OVx animals, both obese, increased vascular permeability and myeloperoxidase (MPO) activity in the intestine and lung, in addition to increasing the cell infiltrate in the lung. An increase in circulating lymphocytes, granulocytes and platelets was observed. We also found elevated serum levels of leptin, interleukin (IL) IL-17A, KC and vascular endothelial growth factor (VEGF), along with serum reduction of IL-6 and resistin. There was an increase in serum alkaline phosphatase concentration, but not in lactate dehydrogenase (LDH). In the lung we detected augmented levels of nitrites and of iNOS expression. In the lung tissue there was an increase of IL-5 and IL-10 and a reduction of leptin, IL-17A, KC and IL-6. In the adipose tissue increased the concentration of KC, MIP-2, IL-6, leptin and resistin. After the animals were submitted to intestinal IR the parameters analyzed in OVx animals were exacerbated regarding the Non-OVx animals. We also noticed an increase in the production of bone marrow cells, a reduction of the CD $45^{+} / \mathrm{CD} 41^{+}$ complex and an increase in the $\mathrm{CD} 11 \mathrm{~b}^{+} / \mathrm{CD} 162^{+}$complex. We observed increased nitrite and iNOS expression in the lung but decreased expression of eNOS. Intestinal IR in OVx animals increased the serum levels of leptin, IL-17A, KC and reduced of those of resistin. There was also an elevation of lung generation of VEGF and IL-1 $\beta$ while in the adipose tissue the contents of KC, MIP-2, IL-6, leptin, and resistin were elevated.

Taken together, our data suggest that the prolonged reduction of $\mathrm{FSH}$ caused by OVx in association with obesity induces to a certain degree of intestinal, systemic and pulmonary inflammation and that the intestinal IR can increase inflammation and the lung is possibly more sensitive.

Keywords: Obesity. Ovariectomy. Female Sex Hormones. Lung Inflammation. Intestinal Ischemia/Reperfusion. 


\section{INTRODUÇÃO}

\subsection{Obesidade e Inflamação}

A obesidade é uma doença multifatorial caracterizada por acúmulo anormal ou excessivo de gordura em consequência à uma disfunção crônica do balanço energético apresentando grande risco à saúde (VIGITEL, 2012). O aumento excessivo de gordura corpórea é um dos mais importantes problemas de saúde pública e se tornou uma epidemia global. Há registros de que $12 \%$ da população mundial é obesa, ou seja, meio bilhão de pessoas segundo dados da OMS (WORLD HEALTH ORGANIZATION (WHO), 2012). Fatores genéticos, ambientais e o estilo de vida como: comportamento social, mudanças no hábito alimentar e o sedentarismo, desempenham um papel importante no desenvolvimento da obesidade (CARVALHO-FILHO et al., 2011). Desta forma, podemos associa-la ao desencadeamento de várias patologias, como resistência a insulina, hipertensão arterial, diabetes mellitus tipo 2, doenças cardiovasculares, câncer, doenças respiratórias e osteoartrite (ABALLAY et al., 2013; ALAM; NG; LARBI, 2012; KOPELMAN, 2000)

Para se caracterizar um indivíduo obeso, a OMS estabelece que a relação peso/altura de um indivíduo adulto, representa o índice aproximado de classificação de sobrepeso ou obesidade. Sendo assim, o Índice de Massa Corporal (IMC) como a relação entre o peso dividido pelo quadrado da altura $\left(\mathrm{kg} / \mathrm{m}^{2}\right)$. Na figura 1 observase a relação entre altura e peso do indivíduo caracterizando-o conforme seu IMC. Um estudo proposto por $\mathrm{Ng}$ et al. (2014) relatou que no período de 1980 a 2013 o número de indivíduos com sobrepeso e obesos aumentou de 857 milhões em 1980 para 1 bilhão em 2013. Segundo a Organização Mundial da Saúde (OMS), estimou que no ano de 2014 mais de 1,9 bilhões de pessoas estavam com sobrepeso e destas, 600 milhões eram obesos (WHO, 2015). 


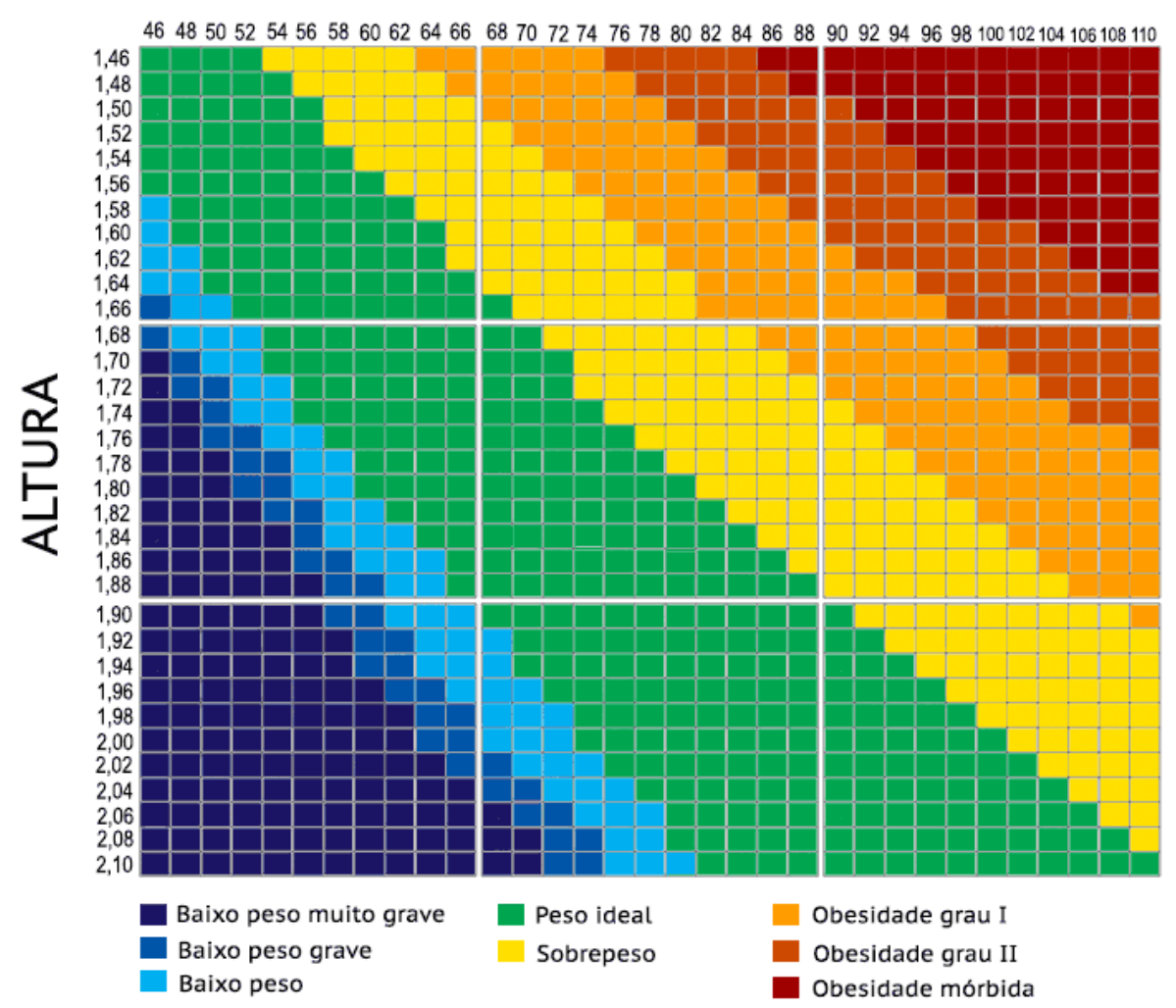

Fonte: http://www.mdsaude.com/2014/10/imc-indice-de-massa-corporal.html Figura 1 - A relação peso/altura do indivíduo conforme o IMC.

Estudos conduzidos no Brasil pelo Ministério da Saúde revelaram aumento de $23 \%$ na frequência de excesso de peso no período 2006 a 2014. Sendo que 2006 a população apresentava 43\% de sobrepeso e $11,9 \%$ de obesos e no período de 2014 estavam com $53 \%$ de sobrepeso e $17,9 \%$ de obesos. Ainda observa-se uma tendência de excesso de peso mais acentuada para mulheres (Homens: $2006=$ $48 \%$; $2014=57 \%$; Mulheres: $2006=39 \% ; 2014=49 \%$ ) no período analisado (VIGITEL, 2014). Embora essa porcentagem seja maior nos homens, no período analisado de 2006 a 2014 apresentou aumento de 1\% nas mulheres.

Segundo Hotamisligil, (2006), a obesidade induz um estado inflamatório crônico de baixo grau, caracterizado pela produção de citocinas pró-inflamatórias pelo tecido adiposo. Sendo assim, o tecido adiposo é considerado um órgão endócrino com funções adicionais às de armazenamento de lipídios (GUILHERME et al., 2008). Entre os inúmeros mediadores (citocinas e hormônios) produzidos pelo tecido adiposo podemos citar o fator de necrose tumoral $\alpha$ (TNF- $\alpha$ ), interleucinas (IL6 e IL-1ß), leptina e adiponectina (PRADO et al., 2009). 
O TNF-a é sintetizado pelos adipócitos assim como por macrófagos, sua função está relacionada à resistência a insulina e a incapacidade da mesma de regular o metabolismo de nutrientes (XU et al., 2003). Além disso, num processo inflamatório como, por exemplo, uma isquemia há aumento na produção de TNF-a e IL-1 $\beta$ pelas células endoteliais. Estas células quando ativadas expressam moléculas de adesão auxiliando a migração dos leucócitos (DO et al., 1999). Outro efeito importante do TNF- $\alpha$ é regular a geração de citocinas como a IL-6 e IL-10. A IL-6 é sintetizada pelo tecido adiposo, fibroblastos, monócitos e células endoteliais (BASTARD et al., 2007). Esta, por sua vez, estimula a síntese de proteínas de fase aguda pelos hepatócitos e a produção de neutrófilos por seus progenitores na medula óssea (OLIVEIRA et al., 2011).

Por outro lado, a adiponectina é uma citocina anti-inflamatória sintetizada pelos tecidos adiposos, células do músculo esquelético, células endoteliais e pelo encéfalo. Assim, em indivíduos saudáveis a adiponectina está presente na circulação em altas concentrações enquanto em indivíduos obesos sua concentração é baixa. Aparentemente isto decorre por conta dos níveis de TNF- $\alpha$ e IL-6 estarem altos, pois estes inibem a transcrição de adiponectina (KURYSZKO; SŁAWUTA; SAPIKOWSKI, 2016; TILG; MOSCHEN, 2006). Outro estudo envolvendo humanos e roedores obesos, também mostrou que o aumento do tecido adiposo reduz os níveis de adiponectina no próprio tecido adiposo e também no soro (OUCHI et al., 1999). A redução desta citocina no plasma de humanos está relacionada com o risco de doenças cardiovasculares, hipertensão, dislipidemia e diabetes (FUNAHASHI et al., 2004).

A IL-10 também possui ação anti-inflamatória, esta citocina é sintetizada por macrófagos e linfócitos, uma das suas funções é inibir a síntese de citocinas proinflamatórias. Na obesidade, apresenta-se em baixa concentração enquanto a diminuição do peso pode elevar os níveis de adiponectina e IL-10 e reduzir os níveis de TNF- $\alpha$ e IL-6 (ARSLAN; ERDUR; AYDIN, 2010). Foi demonstrado em humanos que a adiponectina induz a expressão de IL-10 em macrófagos na inflamação e síndrome metabólica (NISHIDA et al., 2007).

A leptina é um hormônio sintetizado pelo tecido adiposo e está envolvida no controle da ingestão de alimentos e gasto energético por meio de sinalização no sistema nervoso central, especialmente no hipotálamo (AHIMA et al., 1996; ARAÚJO et al., 2011; CHAN et al., 2003). Sua ação imunomoduladora consiste na indução da 
síntese de citocinas pró-inflamatórias tais como TNF- $\alpha$, IL-6, e fator de crescimento do tipo 1. O inverso igualmente ocorre, isto é, o TNF- $\alpha$ e a IL-1 $\beta$ podem induzir aumento da concentração circulante de leptina (OUCHI et al., 2011). Ainda, a leptina estimula a geração de citocinas com perfil Th$h_{1}$, como a IL-2 e interferon tipo y (INFY), e inibe aquelas conhecidas como sendo de perfil Th 2 , como a IL-4 (LORD et al., 1998). É interessante notar que adipócitos de mulheres secretam mais leptina do que adipócitos de homens (ELMQUIST; SCHERER, 2012). Isto pode estar relacionado ao IMC, pois as mulheres tendem a ter maior porcentagem de gordura em relação aos homens (KENNEDY et al., 1997).

Estudos conduzidos por Ainslie et al. (2000); Surwit et al. (1995) demonstraram que uma dieta rica em gordura diminui os níveis de leptina no plasma de animais e como consequência, reduz a saciedade e leva a ingestão excessiva de alimentos. Lomba et al. (2010) mostraram que animais submetidos por 69 dias com dieta hiperlipídica apresentaram aumento do peso corporal, adiposidade e tolerância à glicose diminuída.

Zúñiga et al. (2010) indicaram que a IL-17, também conhecida como IL-17A, uma citocina sintetizada principalmente por célula $T C D 4+$, reduz a formação e o acúmulo de tecido adiposo e também controla o metabolismo da glicose. De fato, camundongos obesos, deficientes de IL-17 aumentam a quantidade de massa de tecido adiposo. Ainda, a deficiência de IL-17 pode causar hiperglicemia em jejum. É interessante notar que há uma relação entre a deficiência da IL-17 com o acúmulo de tecido adiposo, entretanto esta deficiência reduz a inflamação sistêmica.

Como mencionado, a obesidade determina um estado inflamatório crônico de baixo grau. Neste contexto, Ferrante, (2007) descreveu que indivíduos obesos apresentam elevado índice basal de mediadores inflamatórios no tecido adiposo e por decorrência têm maior propensão a um prognóstico desfavorável quando acometidos por trauma ou sepse. A inflamação observada na obesidade também pode predispor pacientes à lesão pulmonar aguda na vigência de sepse (MCCALLISTER; ADKINS; O'BRIEN, 2009). A obesidade também pode levar a complicações na complacência pulmonar, alterações nas trocas gasosas e no comprimento torácico-abdominal, sendo assim pode desencadear insuficiência respiratória e lesão pulmonar aguda (NAIMARK; CHERNIACK, 1960).

Tomados em conjunto os dados indicam que a obesidade se associa ao desenvolvimento de doenças metabólicas e inflamação sistêmica sendo, portanto de 
interesse estudos que investiguem a interação da obesidade com eventos indutores de inflamação sistêmica tais como observado na isquemia e reperfusão intestinal.

$\mathrm{Na}$ IR intestinal o primeiro órgão afetado é o intestino delgado que sofre a isquemia da artéria mesentérica superior (AMS). Este segmento intestinal é responsável pela maior parte da digestão de nutrientes bem como sua absorção. Nesse sentido, existem evidências experimentais de que há relação entre a obesidade e o desenvolvimento de inflamação intestinal. Vale lembrar que a dieta hiperlipídica altera a microbiota e a barreira epitelial podendo originar a inflamação (DE LA SERRE et al., 2010). É interessante notar que crianças obesas desenvolvem inflamação intestinal com quebra da barreira da mucosa intestinal, induzindo migração de leucócitos para o lúmen intestinal e geração de óxido nítrico (SPAGNUOLO et al., 2010).

Num estudo experimental, animais mantidos sob dieta hiperlipídica foi notada alterações na microbiota com aumento da concentração circulante de LPS (Lipopolissacarídeo: toxina derivada da membrana externa de bactérias Gramnegativas) com consequente, inflamação intestinal. Após esses animais serem submetidos ao tratamento com antibiótico o quadro se reverteu e houve diminuição das bactérias e dos níveis de LPS circulantes (CARVALHO et al., 2012). Vale ressaltar, que o LPS atua pela via do receptor toll-like 4 (TLR-4), um subtipo de proteína transmenbrânica dos receptores toll-like, iniciando eventos inflamatórios, bem como induz geração de citocinas pró-inflamatórias como a IL-6 e o TNF- $\alpha$. Portanto, o LPS desencadeia uma inflamação intestinal encontrada no estudo mencionado (DE LA SERRE et al., 2010).

\subsection{Isquemia e Reperfusão Intestinal e Inflamação Pulmonar}

A isquemia é caracterizada pela interrupção total ou parcial do fluxo sanguíneo levando a alterações do metabolismo, já a reperfusão é a restauração deste fluxo (ELTZSCHIG; ECKLE, 2011). Durante a fase de isquemia ocorre a diminuição do oxigênio impedindo a produção de ATP (trifosfato de adenosina) e de nutrientes. A falta de ATP implica em acúmulo de sódio e cálcio intracelular gerando efeitos deletérios para a célula, como alterações da permeabilidade vascular (edema), liberação de metabólitos, produção de radicais livres, entre outros que contribuirão para morte celular (OKUDA et al., 1992; RIO et al., 2000; WAXMAN, 1996). Em decorrência da isquemia macrófagos, células endoteliais e diversos 
mediadores induzem a geração de espécies reativas de oxigênio, ativam o fator nuclear kappa B (NF-kB) e óxido nítrico sintases (NOS) (BECKERS et al., 2017).

Desta forma o processo de reperfusão da área isquêmica é importante para que seja restabelecida a homeostasia. Contudo a reperfusão parece ser evento crítico para o organismo, pois é nesta fase que mediadores infamatórios produzidos pela isquemia disseminam para a circulação causando danos adicionais aos tecidos (DO et al., 1999). Durante o período de reperfusão ocorre aumento da produção de espécies reativas de oxigênio (REILLY; SCHILLER; BULKLEY, 1991; ZIMMERMAN; GRANGER, 1994), ativação de leucócitos e moléculas de adesão as quais auxiliam no transporte e migração de células para o local de inflamação. Assim moléculas de adesão intercelular tipo 1 e 2 (ICAM-1 e ICAM-2), endotelial plaquetária tipo 1 (PECAM-1) e celular vascular (VCAM) exercem importante papel nos eventos isquêmicos seguidos da reperfusão (DO et al., 1999; EVORA et al., 1996; MCCORD; MCCORD, 1985). Os produtos tóxicos gerados após a IR intestinal causam lesões no tecido e microvasculatura intestinal e, nos vasos mesentéricos (GORDEEVA et al., 2017). É descrito na literatura que $3 \mathrm{~h}$ de isquemia intestinal seguidas de $1 \mathrm{~h}$ de reperfusão desencadeia maior lesão na mucosa do intestino do que somente $4 \mathrm{~h}$ de isquemia intestinal (PARKS; GRANGER, 1986).

A IR intestinal é um fenômeno de ocorrências clínicas como naquelas que exigem oclusão da artéria mesentérica, transplante de intestino, cirurgias vasculares e trauma seguido por choque hemorrágico (CHEN et al., 2003). Há relatos que tais eventos provoquem lesão da barreira intestinal (LU et al., 2017) permitindo assim, translocação das bactérias presentes no intestino para o sistema circulatório resultando em inflamação sistêmica (FINK; DELUDE, 2005). A incidência de mortalidade por eventos isquêmicos é alta apresentando uma taxa de $60-80 \%$ dos casos (VOLLMAR; MENGER, 2011).

É importante salientar que estudos clínicos e experimentais relatam que danos causados pela IR intestinal levam a alterações no pulmão (AN et al., 2007). Estes dados portanto, demonstram que uma das consequências da IR intestinal é o desencadeamento de inflamação pulmonar aguda a qual pode evoluir, em casos mais graves para a síndrome do desconforto respiratório agudo, inflamação sistêmica e falência múltipla de órgãos e sistemas (BARON et al., 1994; HSIEH et al., 2011; JAMES et al., 2010). 
Neste contexto, observa-se aumento da permeabilidade vascular pulmonar e intestinal, infiltração de neutrófilos no pulmão, elevação da concentração de TNF-a, IL-1 $\beta$, IL-6 circulantes, óxido nítrico, leucotrieno B4 $\left(\mathrm{LTB}_{4}\right)$ entre outros mediadores. Além disso, modifica a expressão PECAM-1 (BREITHAUPT-FALOPPA et al., 2012; HE et al., 2012; MORAES et al., 2008; VOLLMAR; MENGER, 2011). A ativação de neutrófilos, plaquetas, aumento da permeabilidade vascular e expressão de ICAM-1 no pulmão após a IR intestinal também já foram elucidados (GRACE, 1994; KUZU et al., 2002).

Outros estudos discutiram a participação do óxido nítrico no aumento de permeabilidade vascular (BREITHAUPT-FALOPPA et al., 2009; CAVRIANI et al., 2004) e recrutamento de neutrófilos no tecido pulmonar após a IR intestinal (CAVRIANI et al., 2004). O óxido nítrico é sintetizado pela L-arginina por meio da ação da NOS que é expresso pela enzima óxido nítrico sintase induzida (iNOS) e por duas enzimas óxido nítrico sintase constitutivas (cNOS) e em condições normais o NO desempenha papel importante na homeostasia vascular (BECKERS et al., 2017). Não obstante, o excesso de NO leva a consequências patológicas (CUZZOCREA et al., 2002). O aumento do NO é expresso também pelo aumento da iNOS sendo relacionados a IR e lesão pulmonar induzida por LPS (GRACE, 1994; NUMATA et al., 1998). De acordo com Virlos et al. (2003) a IR intestinal exacerbou no pulmão a expressão de iNOS e atenuou a expressão do óxido nítrico sintase endotelial (eNOS). A eNOS é uma enzima constitutiva, expressa em condições normais no endotélio vascular (CERQUEIRA; YOSHIDA, 2002). Também foi demonstrado por $\mathrm{Li}$ et al. (2011) em modelo de IR intestinal que a inibição da via Rho quinase eleva no pulmão a expressão de eNOS e reduz a concentração sérica de TNF- $\alpha$ e IL-6 e da enzima MPO, enzima que expressa a presença de neutrófilos, no tecido pulmonar. Outra NOS constitutiva é a óxido nítrico sintase neuronal (nNOS) que não será discutida neste trabalho. Complementando ainda com os dados de Cavriani et al. (2004) as enzimas responsáveis pela produção de NO desempenham diferentes funções e a inibição delas aumenta a lesão pulmonar ocasionado pela IR intestinal desencadeando ativação de neutrófilos e aumento da permeabilidade vascular. De acordo com os autores citados o NO parece exercer um papel importante no modelo mencionado.

As plaquetas também contribuem para lesão causada pela IR intestinal. De acordo com Lapchak et al. (2012) a depleção de plaquetas diminui a lesão intestinal 
e pulmonar causada pela IR intestinal. Plaquetas ativadas podem gerar espécies reativas de oxigênio, interagir com os leucócitos e induzir a expressão de citocinas como a IL-1 $\beta$ (COOPER et al., 2003). Segundo Page; Pitchford, (2013) a formação do complexo neutrófilos e plaquetas auxiliam para o recrutamento de neutrófilos para o sítio inflamatório, pois as plaquetas aumentam a adesão de neutrófilos ao endotélio. Neste estudo investigamos a formação de dois complexos: CD45+/CD41+ e CD11b+/CD162+ (PSGL-1). O marcador CD45+ é expresso em todos os leucócitos, além disso, apresentam maior intensidade nos linfócitos (ALTIN; SLOAN, 1997). O marcador CD41+ é expresso em plaquetas, megacariócitos e células endoteliais, participando da agregação plaquetária (GRANJA et al., 2015). O marcador CD11b+ é expresso em leucócitos, células dendríticas e células natural killer. Regulam a adesão de leucócitos e migração na resposta inflamatória (ROMBOUTS et al., 2016). O marcador CD162 é uma proteína conhecida como ligante de P-selectina (PSGL-1), desempenha um papel importante na adesão e migração de leucócitos (SOO et al., 2009).

Evidências mostram que a inibição da via de sinalização do receptor TLR-4 atenua a lesão intestinal e pulmonar causada pela isquemia e reperfusão intestinal. Este estudo relatou que camundongos deficientes do receptor TLR-4 apresentaram redução de mediadores no intestino como TNF- $\alpha$, IL-6, IL-1 $\beta$ e NF-KB e no pulmão como NO, iNOS, MCP-1, MIP-2 e NF-KB (ZHU et al., 2017). Além disso, também foi demonstrado que a inibição TLR-4 reduz a lesão de IR no fígado, rim e intestino (CHEN et al., 2008; SHIGEOKA et al., 2007; ZHAl et al., 2004). A expressão elevada do receptor TLR-4 e do NF-kB estão relacionados com eventos que medeiam a IR intestinal indicando também infiltração de neutrófilos e linfócitos e aumento de MIP2, MCP-1, entre outras quimiocinas analisadas no intestino após a IR intestinal (WATSON et al., 2008).

Considerando o exposto é razoável avaliar que estudos sobre a IR intestinal são de interesse para compreensão dos mecanismos subjacentes à lesão intestinal e pulmonar e para o desenvolvimento de terapias a fim de reduzir o índice de mortalidade.

\subsection{Hormônios Sexuais Femininos (HSF)}

Os hormônios sexuais tem importante influência na regulação do metabolismo de adipócitos (LIZCANO; GUZMÁN, 2014). A redução dos seus níveis circulantes 
acarreta em distúrbios endócrinos e funcionais (STUDD, 1989), assim como disfunção sexual, alterações nos níveis de lipoproteínas, aumento no risco de osteoporose, doenças cardiovasculares e diabete mellitus tipo 2 (CARR, 2003; MAUVAIS-JARVIS, 2011; VASCONCELLUS et al., 2004). Estudos avaliam o papel da diminuição do estrogênio circulante como evento modulador do desenvolvimento da obesidade (CLEGG, 2012). Num estudo conduzido por Flegal et al. (2010) observa-se que americanas após atingirem os 40 anos aumentaram o risco de desenvolver obesidade sendo esta, fortemente relacionada com o desenvolvimento de doenças cardiovasculares. De fato, dados mostram que esse aumento chega a $65 \%$ em mulheres entre 40 e 59 anos de idade e 73,8\% naquelas acima de 60 anos. Evidências clínicas e experimentais mostram que a redução do estrogênio contribui para resistência à insulina. Ainda, no contexto da modulação do metabolismo, existem dados que o estrogênio contribui para a manutenção do balanço energético e metabolismo de glicose (KIM; CHO; KIM, 2014).

Estudos demonstram que a modulação da resposta imune (Th1 e Th2) está relacionada ao ciclo menstrual, onde o perfil Th1 da resposta tende a ser dominante durante a menstruação e na fase lútea do ciclo sexual. Em contraste, na fase folicular o perfil Th2 se sobrepõe ao Th1. Esta modulação pode estar associada a doenças como esclerose múltipla e artrite reumatoide. Assim parece que os HSF, ao exercerem atividade moduladora do sistema imune, podem igualmente interferir com o curso da resposta inflamatória. (FISH, 2008). Ainda, distúrbios cardiovasculares são mais graves em mulheres na pós-menopausa (STANGL; BAUMANN; STANGL, 2002). Evidências clínicas revelam que mulheres hormonalmente ativas apresentam menor incidência de pneumonia, sepse e falência de múltiplos órgãos em relação aos homens (DEITCH et al., 2007; MEES et al., 2008; SPERRY et al., 2008). Estudos experimentais também mostraram a importância dos HSF na inflamação alérgica pulmonar (DE OLIVEIRA et al., 2007; LINO-DOS-SANTOS-FRANCO et al., 2011; TAM et al., 2011).

Estudos também mostram a participação dos HSF na modulação das repercussões pulmonares causadas pelo trauma seguido de choque hemorrágico (ANGELE; FRANTZ; CHAUDRY, 2006; HILDEBRAND et al., 2006; MELDRUM, 2006; MOEINPOUR et al., 2007). Dentre estes estudos, devemos destacar o trabalho de Frink et al. (2006) que mostrou que mulheres com trauma intestinal 
geram menores concentrações séricas de citocinas inflamatórias, em relação aos homens e que isto reduz o risco de desenvolvimento de falência múltipla de órgãos.

Estudos realizados em nosso laboratório indicaram que fêmeas OVx apresentam piora em seu estado inflamatório após serem submetidos a IR intestinal em comparação as fêmeas com os ovários intactos. Além disso, machos e fêmeas OVx ao serem submetidos ao tratamento com estradiol apresentam uma melhora no perfil inflamatório mostrando assim, a importância deste esteroide (BREITHAUPTFALOPPA et al., 2013, 2014; FANTOZZI et al., 2017; RICARDO-DA-SILVA et al., 2017). É interessante ressaltar que, dados não publicados obtidos anteriormente em nosso laboratório, observamos em modelo de IR intestinal que camundongos fêmeas com ovários intactos mantidas sob dieta hiperlipídica não apresentam quadro inflamatório pulmonar após $2 \mathrm{~h}$ de reperfusão intestinal. Todavia, após $24 \mathrm{~h}$ de reperfusão intestinal observa-se inflamação pulmonar, com aumento de edema e recrutamento de neutrófilos, o que sugere uma resposta de inflamação mais tardia nos animais obesos.

À luz dessas evidências é de interesse investigar o papel da obesidade que causa inflamação de baixo grau e que os hormônios sexuais femininos parecem modular a inflamação causada pela IR intestinal e, portanto estudos que associem a obesidade com os HSF no trauma isquêmico intestinal se revestem de importância adicional. 


\section{CONCLUSÃO}

Os dados gerados neste estudo permitem concluir que:

Camundongos fêmeas C57BL/6 submetidas a dieta hiperlipídica por 9 semanas ficaram obesas e, a remoção dos ovários reduziu, após o mesmo período, os níveis séricos de estradiol. Além disso, a remoção dos ovários acentuou o ganho de peso dos animais bem como os níveis circulantes de colesterol e triglicérides em comparação aos observado em animais com ovários intactos. É possivel portanto que a remoção dos ovários exacerba o quadro de obesidade.

Os hormônios sexuais femininos e a obesidade parecem modular a permeabilidade vascular e o recrutamento de neutrófilos intestinal e este evento ocorre de forma semelhante após a IR intestinal.

O perfil de leucócitos circulantes nos animais sob IR intestinal também parece ser controlado pelos hormônios sexuais femininos enquanto o perfil de linfócitos, granulócitos e plaquetas parecem estar sob influência conjunta da obesidade e dos hormônios sexuais femininos.

O organismo pode ter se tornado mais sensível a estímulos lesivos visto o aumento de fosfatase alcalina causado pela remoção dos ovários. Além disso, a remoção dos ovários aumentou os níveis circulantes de leptina, IL-17A, KC e VEGF e reduziu aqueles de IL-6 e resistina. A IR intestinal aumentou a concentração de leptina, IL-17A e KC a qual parece ser controlada pela interação dos hormônios sexuais femininos/obesidade.

A remoção dos ovários interfere com a formação de complexos de plaqueta com leucócitos podendo reduzir $\left(\mathrm{CD} 45^{+} / \mathrm{CD} 41^{+}\right)$ou aumentar $\left(\mathrm{CD} 11^{+} / \mathrm{CD} 162^{+}\right)$após a IR intestinal. Com isto, a redução do complexo leucócitos plaquetas após a IR intestinal nos sugere que estas células estão sendo recrutadas para o stítio inflamatório, e pode justificar o aumento da atividade de MPO intestinal, pulmonar e o aumento do infiltrado de células no pulmão. 
A permeabilidade vascular pulmonar, mas não a formação de edema parece depender dos hormônios sexuais femininos na obesidade. Ainda, sugere-se que no tecido pulmonar, o recrutamento de neutrófilos está sob controle da interação obesidade/hormônios sexuais femininos e de forma semelhante após a IR intestinal.

A redução da concentração de IL-17A, KC, IL-6 e leptina bem como o aumento da geração de IL5 e IL-10 no tecido pulmonar de animais com ovários removidos parece ser mediada pelos HSF em animais obesos. A IR intestinal aumentou os níveis de VEGF e IL-1 $\beta$ no pulmão sugerindo uma interação da obesidade com os hormônios sexuais femininos.

A geração de nitrito eleva em animais obesos sem ovários e pode ser modulada pela atividade de iNOS. Após a IR intestinal este evento ocorreu de forma similar.

A IR intestinal em animais com os ovários removidos manteve a atividade de iNOS elevada mas reduziu a atividade de eNOS, eventos que podem contribuir para a inflamação pulmonar nos animais obesos.

O tecido adiposo de animais obesos desprovidos de ovários aumentou a geração de KC, MIP-2, IL-6, leptina e resistina, sendo que o mesmo ocorreu após a IR intestinal.

Os dados sugerem interação da obesidade com os hormônios sexuais femininos a qual pode modular a sensibilidde aos efeitos locais, sistêmicos e pulmonar decorrentre da IR intestinal. 


\section{REFERÊNCIAS*}

ABALLAY, L. R. et al. Overweight and obesity: a review of their relationship to metabolic syndrome, cardiovascular disease, and cancer in South America. Nutrition reviews, v. 71, n. 3, p. 168-179, mar. 2013.

ABU-TAHA, M. et al. Menopause and ovariectomy cause a low grade of systemic inflammation that may be prevented by chronic treatment with low doses of estrogen or losartan. Journal of Immunology (Baltimore, Md. : 1950), v. 183, n. 2, p. 13931402, 15 jul. 2009.

ACCETTURI, B. G. Avaliação do papel dos hormônios sexuais femininos em modelo murino de asma experimental. 2014. 111f. Tese (Doutorado em Farmacologia). Instituto de Ciências Biomédicas, Universidade de São Paulo, São Paulo, 2014.

AHIMA, R. S. et al. Role of leptin in the neuroendocrine response to fasting. Nature, v. 382, n. 6588, p. 250-252, 18 jul. 1996.

AINSLIE, D. A. et al. Short-term, high-fat diets lower circulating leptin concentrations in rats. The American Journal of Clinical Nutrition, v. 71, n. 2, p. 438-442, fev. 2000.

ALAM, I.; NG, T. P.; LARBI, A. Does Inflammation Determine Whether Obesity Is Metabolically Healthy or Unhealthy? The Aging Perspective. Mediators of Inflammation, v. 2012, p. 1-14, 2012.

ALTIN, J. G.; SLOAN, E. K. The role of CD45 and CD45-associated molecules in T cell activation. Immunology and Cell Biology, v. 75, n. 5, p. 430-445, out. 1997.

AN, S. et al. Lung injury after ischemia-reperfusion of small intestine in rats involves apoptosis of type II alveolar epithelial cells mediated by TNF- $\alpha$ and activation of Bid pathway. Apoptosis, v. 12, n. 11, p. 1989-2001, 28 set. 2007.

ANFOSSI, G. et al. Adipocytokines in atherothrombosis: focus on platelets and vascular smooth muscle cells. Mediators of Inflammation, v. 2010, p. 174341, 2010.

ANGELE, M. K.; FRANTZ, M. C.; CHAUDRY, I. H. Gender and sex hormones influence the response to trauma and sepsis: potential therapeutic approaches. Clinics (Sao Paulo, Brazil), v. 61, n. 5, p. 479-488, out. 2006.

ARAÚJO, E. P.; MORAES, J. C. Adipocitocinas e Controle da Ingestão Alimentar. CINTRA, D. E. ROPELLE, E. R.; PAULI, J. R. Obesidade e Diabetes: Fisiopatologia e Sinalização Celular. Editora: Sarvier. Cap.7 pág.126, 2011.

\footnotetext{
* De acordo com:

ASSOCIAÇÃO BRASILEIRA DE NORMAS TÉCNICAS. NBR 6023: informação e documentação: referências: elaboração. Rio de Janeiro, 2002.
} 
ARNALICH, F. et al. Relationship of plasma leptin to plasma cytokines and human survivalin sepsis and septic shock. The Journal of Infectious Diseases, v. 180, n. 3, p. 908-911, set. 1999.

ARSLAN, N.; ERDUR, B.; AYDIN, A. Hormones and cytokines in childhood obesity. Indian Pediatrics, v. 47, n. 10, p. 829-839, out. 2010.

BARON, P. et al. Gut Failure and Translocation Following Burn and Sepsis. Journal of Surgical Research, v. 57, n. 1, p. 197-204, jul. 1994.

BASTARD, J.-P. et al. Point-counterpoint: Interleukin-6 does/does not have a beneficial role in insulin sensitivity and glucose homeostasis. Journal of Applied Physiology (Bethesda, Md. : 1985), v. 102, n. 2, p. 821-825, fev. 2007.

BECKERS, P. A. J. et al. Lung ischemia reperfusion injury: the therapeutic role of dipeptidyl peptidase 4 inhibition. Annals of Translational Medicine, v. 5, n. 6, p. 129-129, mar. 2017.

BELLMEYER, A. et al. Leptin resistance protects mice from hyperoxia-induced acute lung injury. American Journal of Respiratory and Critical Care Medicine, v. 175, n. 6, p. 587-594, 15 mar. 2007.

BENEDUSI, V. et al. Ovariectomy shortens the life span of female mice. Oncotarget, v. 6, n. 13, p. 10801-10811, 10 maio 2015.

BREITHAUPT-FALOPPA, A. C. et al. Nitric oxide mediates lung vascular permeability and lymph-borne il-6 after an intestinal ischemic insult. Shock, v. 32, n. 1, p. 55-61, jul. 2009.

BREITHAUPT-FALOPPA, A. C. et al. Intestinal lymph-borne factors induce lung release of inflammatory mediators and expression of adhesion molecules after an intestinal ischemic insult. The Journal of Surgical Research, v. 176, n. 1, p. 195201, jul. 2012.

BREITHAUPT-FALOPPA, A. C. et al. Protective effect of estradiol on acute lung inflammation induced by an intestinal ischemic insult is dependent on nitric oxide. Shock, v. 40, n. 3, p. 203-209, set. 2013.

BREITHAUPT-FALOPPA, A. C. et al. Acute Effects of Estradiol on Lung Inflammation Due to Intestinal Ischemic Insult in Male Rats. Shock, v. 41, n. 3, p. 208-213, mar. 2014.

BRYSON, J. M. et al. Plasma insulin rise precedes rise in ob mRNA expression and plasma leptin in gold thioglucose-obese mice. The American Journal of Physiology, v. 276, n. 2 Pt 1, p.358-364, fev. 1999.

CAMPOS, D. H. S. DE et al. Obesity Preserves Myocardial Function During Blockade of the Glycolytic Pathway. Arquivos Brasileiros de Cardiologia, v. 103, n. 4, p. 330-337, 2014. 
CARR, M. C. The Emergence of the Metabolic Syndrome with Menopause. The Journal of Clinical Endocrinology \& Metabolism, v. 88, n. 6, p. 2404-2411, jun. 2003.

CARVALHO-FILHO, et al. Obesidade e Diabetes da Origem ao Caos. CINTRA, D. E.; ROPELLE, E. R.; PAULI, J. R. Obesidade e Diabetes: Fisiopatologia e Sinalização Celular. Editora: Sarvier, Cap.1 pág.3, 2011.

CARVALHO, B. M. et al. Modulation of gut microbiota by antibiotics improves insulin signalling in high-fat fed mice. Diabetologia, v.55, p.2823-2834, 2012.

CARVALHO, J. L. et al. Beneficial effect of low-level laser therapy in acute lung injury after $\mathrm{i}-\mathrm{I} / \mathrm{R}$ is dependent on the secretion of IL-10 and independent of the TLR/MyD88 signaling. Lasers in Medical Science, v. 32, n. 2, p. 305-315, 6 fev. 2017.

CAVRIANI, G. et al. Lung microvascular permeability and neutrophil recruitment are differently regulated by nitric oxide in a rat model of intestinal ischemia-reperfusion. European Journal of Pharmacology, v. 494, n. 2-3, p. 241-249, 28 jun. 2004.

CAVRIANI, G. et al. Lymphatic system as a path underlying the spread of lung and gut injury after intestinal ischemia/reperfusion in rats. Shock, v. 23, n. 4, p. 330-336, abr. 2005.

CAVRIANI, G. et al. Lymphatic thoracic duct ligation modulates the serum levels of il$1 \beta$ and il-10 after intestinal ischemia/reperfusion in rats with the involvement of tumor necrosis factor $\alpha$ and nitric oxide. Shock, v. 27, n. 2, p. 209-213, fev. 2007.

CERQUEIRA, N. F.; YOSHIDA, W. B. Óxido nítrico: revisão. Acta Cirurgica Brasileira, v. 17, n. 6, p. 417-423, 2002.

CHALVATZAS, $\mathrm{N}$. et al. Effect of ovarian hormones on serum adiponectin and resistin concentrations. Fertility and Sterility, v. 91, n. 4, p. 1189-1194, abr. 2009.

CHAN, J. L. et al. The role of falling leptin levels in the neuroendocrine and metabolic adaptation to short-term starvation in healthy men. The Journal of Clinical Investigation, v. 111, n. 9, p. 1409-1421, mai. 2003.

CHEN, L.-W. et al. The two faces of IKK and NF-KB inhibition: prevention of systemic inflammation but increased local injury following intestinal ischemia-reperfusion. Nature Medicine, v. 9, n. 5, p. 575-581, mai. 2003.

CHEN, L.-W. et al. TLR ligand decreases mesenteric ischemia and reperfusion injury-induced gut damage through tnf- $\alpha$ signaling. Shock, v. 30, n. 5, p. 563-570, nov. 2008.

$\mathrm{CHU}, \mathrm{M}$. C. et al. Insulin resistance in postmenopausal women with metabolic syndrome and the measurements of adiponectin, leptin, resistin, and ghrelin. American Journal of Obstetrics and Gynecology, v. 194, n. 1, p. 100-104, jan. 2006. 
CLEGG, D. J. Minireview: the year in review of estrogen regulation of metabolism. Molecular Endocrinology (Baltimore, Md.), v. 26, n. 12, p. 1957-1960, dez. 2012.

CONSIDINE, R. V; CARO, J. F. Leptin and the regulation of body weight. The International Journal of Biochemistry \& Cell Biology, v. 29, n. 11, p. 1255-1272, nov. 1997.

COOPER, D. et al. Time-dependent platelet-vessel wall interactions induced by intestinal ischemia-reperfusion. American Journal of Physiology Gastrointestinal and Liver Physiology, v. 284, n. 6, 2003.

CORREIA-JÚNIOR, A.L. Efeitos da associação da ovariectomia com uma dieta hiperlipídica sobre alterações no metabolismo lipídico, remodelamento e redistribuição do tecido adiposo e sobre os marcadores inflamatórios em camundongos C57BL/6. 2011. 68f. Dissertação (Mestrado em Biologia Humana e Experimental). Instituto de Biologia Roberto Alcântara Gomes, Universidade do Rio de Janeiro, Rio de Janeiro, 2011.

CUZZOCREA, S. et al. Role of induced nitric oxide in the initiation of the inflammatory response after postischemic injury. Shock, v. 18, n. 2, p. 169-176, ago. 2002.

DAVID, et al. Sustained nitric oxide production via I-arginine administration ameliorates effects of intestinal ischemia-reperfusion. Journal of Surgical Research, v. 89, n. 1, p. 13-19, mar. 2000.

DE LA SERRE, C. B. et al. Propensity to high-fat diet-induced obesity in rats is associated with changes in the gut microbiota and gut inflammation. American Journal of Physiology. Gastrointestinal and Liver Physiology, v. 299, n. 2, p. 440-448, ago. 2010.

DE OLIVEIRA, A. P. L. et al. Cellular recruitment and cytokine generation in a rat model of allergic lung inflammation are differentially modulated by progesterone and estradiol. American Journal of Physiology. Cell Physiology, v. 293, n. 3, p. 11201128, set. 2007.

DEITCH, E. A. et al. Hormonally active women tolerate shock-trauma better than do men: a prospective study of over 4000 trauma patients. Annals of Surgery, v. 246, n. 3, p. 447-453, set. 2007.

DENG, Z.-H. et al. Leptin relieves intestinal ischemia/reperfusion injury by promoting ERK1/2 phosphorylation and the NO signaling pathway. The Journal of Trauma and Acute Care Surgery, v. 72, n. 1, p. 143-149, jan. 2012.

DENG, Z.-H. et al. Localized leptin release may be an important mechanism of curcumin action after acute ischemic injuries. The Journal of Trauma and Acute Care Surgery, v. 74, n. 4, p. 1044-1051, abr. 2013.

DO, B. et al. Perfusion lung injury. Journal Pneumology, v. 2525, n. 22, p. 124-136, 1999. 
DO, T. T. H. et al. Disturbed intestinal nitrogen homeostasis in a mouse model of high-fat diet-induced obesity and glucose intolerance. American Journal of Physiology. Endocrinology and Metabolism, v. 306, n. 6, p. 668-680, mar. 2014.

DOUCET, D. et al. Estrogen receptor hormone agonists limit trauma hemorrhage shock-induced gut and lung injury in rats. PloS One, v. 5, n. 2, p. 9421, fev. 2010.

EALEY, K. N.; ARCHER, M. C. Elevated circulating adiponectin and elevated insulin sensitivity in adiponectin transgenic mice are not associated with reduced susceptibility to colon carcinogenesis. International Journal of Cancer, v. 124, n. 9, p. 2226-2230, mai. 2009.

ELMQUIST, J. K.; SCHERER, P. E. The cover. Neuroendocrine and endocrine pathways of obesity. Jama, v. 308, n. 11, p. 1070-1071, set. 2012.

ELTZSCHIG, H. K.; ECKLE, T. Ischemia and reperfusion--from mechanism to translation. Nature Medicine, v. 17, n. 11, p. 1391-1401, nov. 2011.

EVORA, P. R. B. et al. Lesão de isquemia-reperfusão. Aspectos patológicos fisiopatológicos e a importância da função endotelial. Arquivos Brasileiros de Cardiologia, v.54, n.4, p. 239-245, 1996.

FANTOZZI, E. T. Hormônios sexuais femininos como moduladores da geração de mediadores inflamatórios em modelo experimental de isquemia e reperfusão intestinal. 2013. 116f. Tese (Mestrado em Farmacologia). Instituto de Ciências Biomédicas, Universidade de São Paulo. São Paulo, 2013.

FANTOZZI, E. T. et al. Estradiol mediates the long-lasting lung inflammation induced by intestinal ischemia and reperfusion. 2017. Manuscrito em andamento.

FERRANTE, A. W. Obesity-induced inflammation: a metabolic dialogue in the language of inflammation. Journal of Internal Medicine, v. 262, n. 4, p. 408-414, out. 2007.

FINK, M. P.; DELUDE, R. L. Epithelial Barrier Dysfunction: A Unifying Theme to Explain the Pathogenesis of Multiple Organ Dysfunction at the Cellular Level. Critical Care Clinics, v. 21, n. 2, p. 177-196, 2005.

FISH, E. N. The X-files in immunity: sex-based differences predispose immune responses. Nature reviews. Immunology, v. 8, n. 9, p. 737-744, set. 2008.

FLEGAL, K. M. et al. Prevalence and trends in obesity among US adults, 1999-2008. Jama, v. 303, n. 3, p. 235-241, jan. 2010.

FOSCHINI, D. et al. Plaqueta e leptina em adolescentes com obesidade. Jornal de Pediatria, v. 84, n. 6, p. 516-521, dez. 2008.

FRANCISCHETTI, I. et al. Os leucócitos e a resposta inflamatória na lesão de isquemia-reperfusão. Revista Brasileira de Cirurgia Cardiovascular, v. 25, n. 4, p. 575-584, dez. 2010. 
FRENETTE, P. S. et al. P-Selectin glycoprotein ligand 1 (PSGL-1) is expressed on platelets and can mediate platelet-endothelial interactions in vivo. The Journal of experimental medicine, v. 191, n. 8, p. 1413-1422, 17 abr. 2000.

FRINK, M. et al. 17beta-Estradiol inhibits keratinocyte-derived chemokine production following trauma-hemorrhage. AJP: Lung Cellular and Molecular Physiology, v. 292, n. 2, p. 585-591, out. 2006.

FUNAHASHI, T.; MATSUZAWA, Y.; KIHARA, S. Adiponectin as a potential key player in metabolic syndrome insights into atherosclerosis, diabetes and cancer. International Congress Series. v.1262, p.368-371, 2004.

GE, X. N. et al. High-fat diet promotes lung fibrosis and attenuates airway eosinophilia after exposure to cockroach allergen in mice. Experimental Lung Research, v. 39, n. 9, p. 365-378, nov. 2013.

GIMENES JUNIOR, J.A. Papel dos hormônios sexuais femininos na inflamação pulmonar aguda e na reatividade das vias aéreas após a instilação nasal de LPS em camundongos. 2013. 161f. Tese (Doutorado em Farmacologia). Instituto de Ciências Biomédicas, Universidade de São Paulo. São Paulo, 2013.

GORDEEVA, A. E. et al. Vascular Pathology of Ischemia/Reperfusion Injury of Rat Small Intestine. Cells, tissues, organs, mar. 2017.

GRACE, P. A. Ischaemia-reperfusion injury. The British Journal of Surgery, v. 81, n. 5, p. 637-647, maio 1994.

GRANJA, T. et al. Using six-colour flow cytometry to analyse the activation and interaction of platelets and leukocytes--A new assay suitable for bench and bedside conditions. Thrombosis Research, v. 136, n. 4, p. 786-796, out. 2015.

GUILHERME, A. et al. Adipocyte dysfunctions linking obesity to insulin resistance and type 2 diabetes. Nature Reviews Molecular Cell Biology, v. 9, n. 5, p. 367377, maio 2008.

GUZMÁN-DE LA GARZA, F. J. et al. Temporal relationship of serum markers and tissue damage during acute intestinal ischemia/reperfusion. Clinics (Sao Paulo, Brazil), v. 68, n. 7, p. 1034-1038, jul. 2013.

HARWOOD, $H$. J. The adipocyte as an endocrine organ in the regulation of metabolic homeostasis. Neuropharmacology, v. 63, n. 1, p. 57-75, jul. 2012.

HE, G. et al. [Impact of glutamine and $\omega-3$ polyunsaturated fatty acids on intestinal permeability and lung cell apoptosis during intestinal ischemia-reperfusion injury in a rat model]. Chinese Journal of Gastrointestinal Surgery, v. 15, n. 5, p. 484-489, mai. 2012.

HEINE, P. A. et al. Increased adipose tissue in male and female estrogen receptoralpha knockout mice. Proceedings of the National Academy of Sciences, v. 97, n. 23, p. 12729-12734, nov. 2000. 
HEREK, O. et al. The effects of intestinal ischemia on the levels of serum immunoglobulin A in rats. Pediatric Surgery International, v. 19, n. 8, p. 601-604, out. 2003.

HERMSDORFF, H. H. M.; MONTEIRO, J. B. R. Gordura visceral, subcutânea ou intramuscular: onde está o problema? Arquivos Brasileiros de Endocrinologia \& Metabologia, v. 48, n. 6, p. 803-811, dez. 2004.

HIERHOLZER, C. et al. Molecular and functional contractile sequelae of rat intestinal ischemia/reperfusion injury. Transplantation, v. 68, n. 9, p. 1244-1254, nov. 1999.

HILDEBRAND, F. et al. Effects of 17beta-estradiol and flutamide on inflammatory response and distant organ damage following trauma-hemorrhage in metestrus females. Journal of Leukocyte Biology, v. 80, n. 4, p. 759-765, out. 2006.

HONG, J. et al. Differential susceptibility to obesity between male, female and ovariectomized female mice. Nutrition Journal, v. 8, n. 1, p. 11, fev. 2009.

HOTAMISLIGIL, G. S. Inflammation and metabolic disorders. Nature, v. 444, n. 7121, p. 860-867, dez. 2006.

$\mathrm{HSIEH}, \mathrm{Y} . \mathrm{H}$. et al. Intestinal ischemia-reperfusion injury leads to inflammatory changes in the brain. Shock, v. 36, n. 4, p. 424-430, out. 2011.

IGNACIO, D. L. et al. [Body mass regulation by estrogen and physical activity]. Arquivos Brasileiros de Endocrinologia e Metabologia, v. 53, n. 3, p. 310-317, abr. 2009.

IWASA, T. et al. The effects of ovariectomy and LPS-induced endotoxemia on resistin levels in female rats. Cytokine, v. 76, n. 2, p. 558-560, dez. 2015.

JAMES, I. A. O. et al. HB-EGF protects the lungs after intestinal ischemia/reperfusion injury. The Journal of Surgical Research, v. 163, n. 1, p. 86-95, set. 2010.

JUNG, C. et al. Alterations in systemic levels of Th1, Th2, and Th17 cytokines in overweight adolescents and obese mice. Pediatric Diabetes, set. 2016.

KAPUR, R. et al. C-reactive protein enhances murine antibody-mediated transfusionrelated acute lung injury. Blood, v. 126, n. 25, p. 2747-2751, dez. 2015.

KENNEDY, A. et al. The metabolic significance of leptin in humans: gender-based differences in relationship to adiposity, insulin sensitivity, and energy expenditure. The Journal of Clinical Endocrinology and Metabolism, v. 82, n. 4, p. 1293-1300, abr. 1997.

KIM, J. H.; CHO, H. T.; KIM, Y. J. The role of estrogen in adipose tissue metabolism: insights into glucose homeostasis regulation. Endocrine Journal, v. 61, n. 11, p. 1055-1067, 2014.

$\mathrm{KOH}, \mathrm{H}$. et al. Protective role of vascular endothelial growth factor in endotoxin- 
induced acute lung injury in mice. Respiratory Research, v. 8, n. 1, p. 60, dez. 2007.

KOPELMAN, P. G. Obesity as a medical problem. Nature, v. 404, n. 6778, p. 635643, abr. 2000.

KORDONOWY, L. L. et al. Obesity is associated with neutrophil dysfunction and attenuation of murine acute lung injury. American Journal of Respiratory Cell and Molecular Biology, v. 47, n. 1, p. 120-127, jul. 2012.

KRETSCHMER, B. D. et al. Modulatory role of food, feeding regime and physical exercise on body weight and insulin resistance. Life Sciences, v. 76, n. 14, p. 15531573, fev. 2005.

KURYSZKO, J.; SŁAWUTA, P.; SAPIKOWSKI, G. Secretory function of adipose tissue. Polish Journal of Veterinary Sciences, v. 19, n. 2, p. 441-446, jan. 2016.

KUZU, M. A. et al. Role of integrins and intracellular adhesion molecule-1 in lung injury after intestinal ischemia-reperfusion. American Journal of Surgery, v. 183, n. 1, p. 70-74, jan. 2002.

LAM, Q. L. K.; LU, L. Role of leptin in immunity. Cellular \& Molecular Immunology, v. 4 , n. 1, p. 1-13, fev. 2007.

LAPCHAK, P. H. et al. Platelets orchestrate remote tissue damage after mesenteric ischemia-reperfusion. American Journal of Physiology. Gastrointestinal and Liver Physiology, v. 302, n. 8, p. 888-897, abr. 2012.

LAPENNA, D.; CUCCURULLO, F. Hypochlorous acid and its pharmacological antagonism: an update picture. General Pharmacology, v. 27, n. 7, p. 1145-1147, out. 1996.

LEITE, L. D. et al. Obesidade: uma doença inflamatória. Revista Ciências \& Saúde, v.2, n.2, p.85-95, 2009.

LI, Y. et al. Inhibition of Rho kinase by fasudil hydrochloride attenuates lung injury induced by intestinal ischemia and reperfusion. Life Sciences, v. 88, n. 1-2, p. 104109, 3 jan. 2011.

LIN, E.; CALVANO, S. E.; LOWRY, S. F. Inflammatory cytokines and cell response in surgery. Surgery, v. 127, n. 2, p. 117-126, fev. 2000.

LINO-DOS-SANTOS-FRANCO, A. et al. Differential effects of female sex hormones on cellular recruitment and tracheal reactivity after formaldehyde exposure. Toxicology Letters, v. 205, n. 3, p. 327-335, set. 2011.

LIZCANO, F.; GUZMÁN, G. Estrogen Deficiency and the Origin of Obesity during Menopause. BioMed Research International, v. 2014, p. 757461, 2014.

LOMBA, A. et al. Weight gain induced by an isocaloric pair-fed high fat diet: a 
nutriepigenetic study on FASN and NDUFB6 gene promoters. Molecular Genetics and Metabolism, v. 101, n. 2-3, p. 273-278, out. 2010.

LORD, G. M. et al. Leptin modulates the T-cell immune response and reverses starvation-induced immunosuppression. Nature, v. 394, n. 6696, p. 897-901, ago. 1998.

LU, Y.-Z. et al. Tumor Necrosis Factor $\alpha$-Dependent Neutrophil Priming Prevents Intestinal Ischemia/Reperfusion-Induced Bacterial Translocation. Digestive Diseases and Sciences, p. 1-13, jan. 2017.

MARKEL, T. A. et al. Human mesenchymal stromal cells decrease mortality after intestinal ischemia and reperfusion injury. The Journal of Surgical Research, v. 199, n. 1, p. 56-66, nov. 2015.

MAUVAIS-JARVIS, F. Estrogen and androgen receptors: regulators of fuel homeostasis and emerging targets for diabetes and obesity. Trends in endocrinology and Metabolism: TEM, v. 22, n. 1, p. 24-33, jan. 2011.

MCCALLISTER, J. W.; ADKINS, E. J.; O'BRIEN, J. M. Obesity and acute lung injury. Clinics in Chest Medicine, v. 30, n. 3, p. 495-508, set. 2009.

MCCORD, J. M.; MCCORD, J. M. Oxygen-derived free radicals in postischemic tissue injury. The New England Journal of Medicine, v. 312, n. 3, p. 159-163, jan. 1985.

MCGUIRE, T. R. et al. Inflammation associated with obesity: relationship with blood and bone marrow endothelial cells. Obesity (Silver Spring, Md.), v. 19, n. 11, p. 2130-2136, nov. 2011.

MEES, S. T. et al. Influence of sex and age on morphological organ damage after hemorrhagic shock. Shock, v. 29, n. 6, p. 670-674, jun. 2008.

MELDRUM, D. R. Estrogen increases protective proteins following trauma and hemorrhage. American Journal of Physiology. Regulatory, Integrative and Comparative Physiology, v. 290, n. 3, p. 809-811, mar. 2006.

MOEINPOUR, F. et al. 17 Beta-estradiol normalizes Toll receptor 4, mitogen activated protein kinases and inflammatory response in epidermal keratinocytes following trauma-hemorrhage. Molecular Immunology, v. 44, n. 13, p. 3317-3323, jul. 2007.

MORAES, L. B. et al. Gut ischemia/reperfusion induced acute lung injury is an alveolar macrophage dependent event. The Journal of Trauma, v. 64, n. 5, p. 11961200-1, mai. 2008.

MOSELEY, T. A. et al. Interleukin-17 family and IL-17 receptors. Cytokine \& Growth Factor Reviews, v. 14, n. 2, p. 155-174, abr. 2003.

NAGASAWA, A. et al. The basis examination of leukocyte-platelet aggregates with 
CD45 gating as a novel platelet activation marker. International Journal of Laboratory Hematology, v. 35, n. 5, p. 534-541, out. 2013.

NAIMARK, A.; CHERNIACK, R. M. Compliance of the respiratory system and its components in health and obesity. Journal of Applied Physiology, v. 15, p. 377382, maio 1960.

NEELS, J. G. et al. Keratinocyte-derived Chemokine in Obesity: Expression, regulation, and role in adipose macrophage infiltration and glucose homeostasis. Journal of Biological Chemistry, v. 284, n. 31, p. 20692-20698, jul. 2009.

NG, K. Y.; YONG, J.; CHAKRABORTY, T. R. Estrous cycle in ob/ob and ovariectomized female mice and its relation with estrogen and leptin. Physiology \& Behavior, v. 99, n. 1, p. 125-130, jan. 2010.

NG, M. et al. Global, regional, and national prevalence of overweight and obesity in children and adults during 1980-2013: a systematic analysis for the Global Burden of Disease Study 2013. Lancet (London, England), v. 384, n. 9945, p. 766-781, ago. 2014.

NIJHUIS, J. et al. Neutrophil Activation in Morbid Obesity, Chronic Activation of Acute Inflammation. Obesity, v. 17, n. 11, p. 2014-2018, nov. 2009.

NISHIDA, M. et al. Interleukin-10 associates with adiponectin predominantly in subjects with metabolic syndrome. Circulation Journal : Official Journal of The Japanese Circulation Society, v. 71, n. 8, p. 1234-1238, ago. 2007.

NOLAN, D. J. et al. Bone marrow-derived endothelial progenitor cells are a major determinant of nascent tumor neovascularization. Genes \& Development, v. 21, n. 12, p. 1546-1558, jun. 2007.

NUMATA, M. et al. Inhibition of inducible nitric oxide synthase prevents LPS-induced acute lung injury in dogs. Journal of Immunology (Baltimore, Md.: 1950), v. 160, n. 6, p. 3031-3037, mar. 1998.

NÜSSLER, N. C. ET AL. IL-10 increases tissue injury after selective intestinal ischemia/reperfusion. Annals of Surgery, v. 238, n. 1, p. 49-58, jul. 2003.

O'DONNELL, C. P. et al. Leptin prevents respiratory depression in obesity. American Journal of Respiratory and Critical Care Medicine, v. 159, n. 5, p. 1477-1484, mai. 1999.

OKUDA, M. et al. Role of extracellular $\mathrm{Ca} 2+$ in ischemia-reperfusion injury in the isolated perfused rat liver. Circulatory Shock, v. 37, n. 3, p. 209-219, jul. 1992.

OLIVEIRA, C. M. B. DE et al. Citocinas e dor. Revista Brasileira de Anestesiologia, v. 61, n. 2, p. 260-265, abr. 2011.

OSTERMAN, C. et al. Platelet-Rich Plasma Increases Anti-inflammatory Markers in a Human Coculture Model for Osteoarthritis. The American Journal of Sports 
Medicine, v. 43, n. 6, p. 1474-1484, jun. 2015.

$\mathrm{OUCHI}, \mathrm{N}$. et al. Novel modulator for endothelial adhesion molecules: adipocytederived plasma protein adiponectin. Circulation, v. 100, n. 25, p. 2473-2476, 1999.

OUCHI, N. et al. Adipokines in inflammation and metabolic disease. Nature Reviews. Immunology, v. 11, n. 2, p. 85-97, fev. 2011.

PAGE, C.; PITCHFORD, S. Neutrophil and platelet complexes and their relevance to neutrophil recruitment and activation. International Immunopharmacology, v. 17, n. 4, p. 1176-1184, 2013.

PARKS, D. A.; GRANGER, D. N. Contributions of ischemia and reperfusion to mucosal lesion formation. The American Journal of Physiology, v. 250, n. 6, p. 749-753, jun. 1986.

PEARSON, L. et al. A rapid flow cytometric technique for the detection of plateletmonocyte complexes, activated platelets and platelet-derived microparticles. International Journal of Laboratory Hematology, v. 31, n. 4, p. 430-439, ago. 2009.

PLACKETT, T. P. et al. Effects of Estrogen on Bacterial Clearance and Neutrophil Response After Combined Burn Injury and Wound Infection. Journal of Burn Care \& Research : Official Publication of The American Burn Association, v. 37, n. 5, p. 328-333, 2016.

PRADO, W. L. DO et al. Obesidade e adipocinas inflamatórias: implicações práticas para a prescrição de exercício. Revista Brasileira de Medicina do Esporte, v. 15, n. 5, p. 378-383, out. 2009.

QU, Y. et al. Interleukin-17A Differentially Induces Inflammatory and Metabolic Gene Expression in the Adipose Tissues of Lean and Obese Mice. International Journal of Molecular Sciences, v. 17, n. 4, p. 522, abr. 2016.

RICARDO-DA-SILVA, F. Y. et al. Estradiol Modulates Local Gut Injury Induced by Intestinal Ischemia-Reperfusion in Male Rats. Shock, p. 1, mar. 2017.

REILLY, P. M.; SCHILLER, H. J.; BULKLEY, G. B. Pharmacologic approach to tissue injury mediated by free radicals and other reactive oxygen metabolites. American Journal of Surgery, v. 161, n. 4, p. 488-503, abr. 1991.

RIO, J. J. et al. Intestinal ischemia-reperfusion injury in horses: pathophysiology and therapeutics. v. 30, n. 6, p. 1083-1093, 2000.

ROMBOUTS, M. et al. Linking CD11b (+) Dendritic Cells and Natural Killer T Cells to Plaque Inflammation in Atherosclerosis. Mediators of Inflammation, v. 2016, p. 112, 2016.

SARSU, S. B. et al. Effects of Leptin on Intestinal Ischemia-Reperfusion Injury. Indian Journal of Surgery, v. 77, n. S2, p. 351-355, dez. 2015. 
S WHITE, P. A. et al. Model of high-fat diet-induced obesity associated to insulin resistance and glucose intolerance. Arquivos Brasileiros de Endocrinologia e Metabologia, v. 57, n. 5, 2013.

SENGER PATRÍCIA FIORINO APOIO, N.; MACKENZIE RESUMO, P. Estudo da morfometria de adipócitos em ratos recém-desmamados submetidos a uma dieta hiperlipídica. VII Jornada de iniciação científica, 2011.

SHARAWY, N. et al. Estradiol receptors agonists induced effects in rat intestinal microcirculation during sepsis. Microvascular Research, v. 85, p. 118-127, jan. 2013.

SHEN, M.; KUMAR, S. P. D. S.; SHI, H. Estradiol regulates insulin signaling and inflammation in adipose tissue. Hormone Molecular Biology and Clinical Investigation, v. 17, n. 2, p. 99-107, fev. 2014.

SHIGEOKA, A. A. et al. TLR2 is constitutively expressed within the kidney and participates in ischemic renal injury through both MyD88-dependent and independent pathways. Journal of Immunology (Baltimore, Md.: 1950), v. 178, n. 10, p. 6252-62588, mai. 2007.

SIFRI, Z. C. et al. Sex hormones affect bone marrow dysfunction after trauma and hemorrhagic shock. Critical Care Medicine, v. 35, n. 3, p. 864-869, mar. 2007.

SILVEIRA, M. R. Correlação entre a obesidade, adipocinas e sistema imunológico. Revista Cineantropom e Desempenho Humano, v.11, n.3, p.466-472, 2009.

SIPPEL, C. et al. Inflammatory processes of obesity. Revista de Atenção à Saúde, v. 12, n. 42, p. 48-56, 2014.

SOARES, A. L. et al. Tumor necrosis factor is not associated with intestinal ischemia/reperfusion-induced lung inflammation. Shock, v. 34, n. 3, p. 306-313, set. 2010.

SOO, A. et al. Pre-operative determination of an individual's neutrophil response: a potential predictor of early cardiac transplant cellular rejection. The Journal of Heart and Lung Transplantation :The Official Publication of The International Society for Heart Transplantation, v. 28, n. 11, p. 1198-1205, nov. 2009.

SÖZEN, S. et al. The effects of glutamine on hepatic ischemia reperfusion injury in rats. Hippokratia, v. 15, n. 2, p. 161-166, abr. 2011.

SPAGNUOLO, M. I. et al. Relationship between severe obesity and gut inflammation in children: what's next? Italian Journal of Pediatrics, v. 36, n. 1, p. 66, out. 2010.

SPERRY, J. L. et al. Characterization of the gender dimorphism after injury and hemorrhagic shock: are hormonal differences responsible? Critical Care Medicine, v. 36, n. 6 , p. 1838-1845, jun. 2008.

SPEYER, C. L. et al. Regulatory effects of estrogen on acute lung inflammation in 
mice. AJP: Cell Physiology, v. 288, n. 4, p. 881-890, dez. 2004.

SPITE, M. et al. Deficiency of the leukotriene B4 receptor, BLT-1, protects against systemic insulin resistance in diet-induced obesity. Journal of Immunology (Baltimore, Md. : 1950), v. 187, n. 4, p. 1942-1949, ago. 2011.

SREERAMKUMAR, V. et al. Neutrophils scan for activated platelets to initiate inflammation. Science (New York, N.Y.), v. 346, n. 6214, p. 1234-1238, dez. 2014.

STANGL, V.; BAUMANN, G.; STANGL, K. Coronary atherogenic risk factors in women. European Heart Journal, v. 23, n. 22, p. 1738-1752, nov. 2002.

STAPLETON, R. D. et al. The association between BMI and plasma cytokine levels in patients with acute lung injury. Chest, v. 138, n. 3, p. 568-577, set. 2010.

STEPPAN, C. M. et al. The hormone resistin links obesity to diabetes. Nature, v. 409, n. 6818, p. 307-312, jan. 2001.

STUBBINS, R. E. et al. Oestrogen alters adipocyte biology and protects female mice from adipocyte inflammation and insulin resistance. Diabetes, Obesity \& Metabolism, v. 14, n. 1, p. 58-66, jan. 2012.

STUDD, J. Prophylactic oophorectomy. BJOG: An International Journal of Obstetrics and Gynaecology, v. 96, n. 5, p. 506-509, mai. 1989.

SUMARAC-DUMANOVIC, M. et al. Increased activity of interleukin-23/interleukin-17 proinflammatory axis in obese women. International Journal of Obesity (2005), v. 33, n. 1, p. 151-156, jan. 2009.

SURWIT, R. S. et al. Differential effects of fat and sucrose on the development of obesity and diabetes in $\mathrm{C} 57 \mathrm{BL} / 6 \mathrm{~J}$ and $\mathrm{A} / \mathrm{J}$ mice. Metabolism: Clinical and Experimental, v. 44, n. 5, p. 645-651, mai. 1995.

TAM, A. et al. The role of female hormones on lung function in chronic lung diseases. BMC Women's Health, v. 11, n. 1, p. 24, dez. 2011.

TAVAF-MOTAMEN, $\mathrm{H}$. et al. Nitric oxide mediates acute lung injury by modulation of inflammation. Journal of surgical research, v. 78, p. 137-142, aug. 1998.

TEKE, Z. et al. Effects of tempol, a membrane-permeable radical scavenger, on local and remote organ injuries caused by intestinal ischemia/reperfusion in rats. The Journal of Surgical Research, v. 149, n. 2, p. 259-271, out. 2008.

THOMAS, S. KARNIK, S. BALASUBRAMANIAN. K. A. Surgical manipulation of the small intestine and its effect on the lung. Journal of Surgical Research, v. 106, p. 145-156, jul. 2002.

THOMPSON, J. S.; BRAGG, L. E.; WEST, W. W. Serum enzyme levels during intestinal ischemia. Annals of Surgery, v. 211, n. 3, p. 369-373, mar. 1990. 
TILG, H.; MOSCHEN, A. R. Adipocytokines: mediators linking adipose tissue, inflammation and immunity. Nature Reviews Immunology, v. 6, n. 10, p. 772-783, 22 out. 2006.

TONG, F. et al. Simvastatin nanoparticles attenuated intestinal ischemia/reperfusion injury by downregulating BMP4/COX-2 pathway in rats. International Journal of Nanomedicine, v. 12, p. 2477-2488, mar. 2017.

TORPY, D. J.; BORNSTEIN, S. R.; CHROUSOS, G. P. Leptin and interleukin-6 in sepsis. Hormone and Metabolic Research, v. 30, n. 12, p. 726-729, dez. 1998.

TURNAGE, R. H. et al. Intestinal reperfusion-induced pulmonary edema is related to increased pulmonary inducible nitric oxide synthase activity. Surgery, v.124, p. 457462, aug. 1998.

TYAGI, A. M. et al. Estrogen deficiency induces the differentiation of IL-17 secreting Th17 cells: a new candidate in the pathogenesis of osteoporosis. PloS One, v. 7, n. 9, p. 44552, 10 set. 2012.

UBAGS, N. D. et al. The role of leptin in the development of pulmonary neutrophilia in infection and acute lung injury. Critical Care Medicine, v. 42, n. 2, p. 143-151, fev. 2014.

VAN DER POLL, T. et al. Endogenous IL-10 protects mice from death during septic peritonitis. Journal of Immunology (Baltimore, Md. : 1950), v. 155, n. 11, p. 53975401, dez. 1995.

VAN NOORD, D. et al. Serum markers and intestinal mucosal injury in chronic gastrointestinal ischemia. Digestive Diseases and Sciences, v. 56, n. 2, p. 506512, fev. 2011.

VASCONCELLUS, L. S. et al. Influencia da ooforectomia na variação ponderal em ratas jovens e adultas. Arquivos Brasileiros de Endocrionologia e Metabologia, v.48, n.2, p.229-304, 2004.

VIGITEL. Vigilância de fatores de risco e proteção para doenças crônicas por inquérito telefônico. Brasília - DF, 2012.

VIGITEL. Vigilância de fatores de risco e proteção para doenças crônicas por inquérito telefônico. Brasília - DF, 2014.

VIRLOS, I. T. et al. Differential expression of pulmonary nitric oxide synthase isoforms after intestinal ischemia-reperfusion. Hepato-Gastroenterology, v. 50, n. 49, p. 31-36, 2003.

VOLLMAR, B.; MENGER, M. D. Intestinal ischemia/reperfusion: microcirculatory pathology and functional consequences. Langenbeck's Archives of Surgery, v. 396, n. 1, p. 13-29, jan. 2011.

WATSON, M. J. et al. Intestinal Ischemia/Reperfusion Injury Triggers Activation of 
Innate Toll-Like Receptor 4 and Adaptive Chemokine Programs. Transplantation Proceedings, v. 40, n. 10, p. 3339-3341, dez. 2008.

WAXMAN, K. Shock: ischemia, reperfusion, and inflammation. New Horizons (Baltimore, Md.), v. 4, n. 2, p. 153-160, maio 1996.

WEISS, S. J. Tissue destruction by neutrophils. The New England Journal of Medicine, v. 9, n. 6, p. 365-376, fev. 1989.

WINER, S. et al. Obesity predisposes to Th17 bias. European Journal of Immunology, v. 39, n. 9, p. 2629-2635, set. 2009.

$\mathrm{XU}, \mathrm{H}$. et al. Chronic inflammation in fat plays a crucial role in the development of obesity-related insulin resistance. The Journal of Clinical Investigation, v. 112, n. 12, p. 1821-1830, dez. 2003.

$\mathrm{YU}, \mathrm{Y}$. et al. Increased inflammatory reaction to intestinal ischemia-reperfusion in neonatal versus adult mice. European Journal of Pediatric Surgery, v. 25, n. 1, p. 46-50, fev. 2015.

ZHAI, Y. et al. Cutting edge: TLR4 activation mediates liver ischemia/reperfusion inflammatory response via IFN regulatory factor 3-dependent MyD88-independent pathway. Journal of Immunology (Baltimore, Md.: 1950), v. 173, n. 12, p. 71157119, dez. 2004.

ZHU, Q. et al. Down-regulation of toll-like receptor 4 alleviates intestinal ischemia reperfusion injury and acute lung injury in mice. Oncotarget, v. 8, n. 8, p. 1367813689 , fev. 2017.

ZIMMERMAN, B. J.; GRANGER, D. N. Mechanisms of reperfusion injury. The American Journal of The Medical Sciences, v. 307, n. 4, p. 284-292, abr. 1994.

ZÚÑIGA, L. A. et al. IL-17 regulates adipogenesis, glucose homeostasis, and obesity. Journal of Immunology (Baltimore, Md.: 1950), v. 185, n. 11, p. $6947-$ 6959, dez. 2010.

WHO.<http://www. who.int/gho/publications/world health statistics/2012/en/>. Acesso em: abril de 2016.

WHO.<http://www.who.int/mediacentre/factsheets/fs311/en/>. Disponível em janeiro de 2015. Acesso em: abril de 2016. 